\title{
LITERATURA NA ESCOLA: PRÁTICA DE INTERPRETAÇÃO?
}

\author{
Maria de Fátima Cruvinel*
}

RESUMO

O objetivo deste trabalho é refletir, a partir da observação de uma experiência escolar, sobre a relação do aluno-leitor com o texto literário mediada pela escola. Considerando certa incompatibilidade entre os discursos literário e pedagógico, a pretensão é avaliar se os jovens alunos alcançam a interpretação, mesmo se a prática leitora é determinada e controlada por um mecanismo de avaliação e seleção como o processo seletivo vestibular. Além do entrecruzamento dos discursos literário e pedagógico, entra na trama um terceiro discurso, o histórico, uma vez que o texto lido, o romance Pão cozido debaixo de brasa, é construído com base em um fato verídico.

Palavras-Chave: literatura, História, vestibular, formação do leitor.

Literature in the school: practice of interpretation?

\section{AbSTRACT}

This work aims at reflecting upon the school mediated relation of the reader-student with the literary text, from observing a school experience. Taking into account some incompatibility between the literary and pedagogic discourses, the intention here is to evaluate if young students reach the interpretation, even if the reading practice is determined and controlled by an evaluation and selection mechanism as the selective process of the university entrance examination. Further on the intercrossing of literary and pedagogic discourses, a third one is inserted in the weft, the Historical discourse, once the read novel Pão cozido debaixo de brasa is built based on a true event. KEY wORDS: literature, History, university entrance examination, reader formation.

a experiência da leitura converte o olhar ordinário sobre o mundo num olhar poético.

(Jorge Larrosa)

\section{DAS PROVOCAÇOÉS}

Afinal, a leitura escolar pode ser vista como prática de interpretação? Em que medida os jovens leitores escolares produzem sentidos e se constituem sujeitos-leitores quando lêem, considerando que essa atividade

* Professora Adjunto da Área de Comunicação do Centro de Ensino e Pesquisa Aplicada à Educação da UFG. E-mail: fatimacruvinel@uol.com.br 


\section{Revista Soltaa Voz, v. 17, n. 2}

circunscreve-se no espaço institucional escolar e, conseqüentemente, encontra-se determinada pelas coerçôes próprias do discurso pedagógico?

E, não nos esquecendo da sensata percepção de Pennac (1998) de que o verbo ler, como o verbo amar, não admite imperativo, como se processa uma atividade de leitura, que deve pressupor um envolvimento mínimo do leitor, cujo objetivo é a competência para a resolução de questões em um processo seletivo do tipo vestibular?

Essas indagaçōes, que penso se apresentarem muito freqüentemente na prática pedagógica do professor de literatura do ensino básico e que são aqui apontadas como provocaçóes que deram origem a este estudo, situam-se tendo como pano de fundo uma prática específica: a leitura do romance Pão cozido debaixo de brasa (Miguel Jorge, 1997), que compõe a lista de leituras obrigatórias para a prova de literatura do processo seletivo/2005 da Universidade Federal de Goiás.

Um dos pressupostos teóricos de que parte esta investigação é o de que a linguagem é um fenômeno social e histórico, é ação dialógica que reflete e refrata o mundo que representa (Bakhtin, 1995), e os enunciados são lingüisticamente descritíveis como séries de pontos de deriva possíveis, oferecendo lugar à interpretação, na medida em que se constituem no entrecruzamento da linguagem e da história (Pêcheux, 1997). Considera-se, assim, para efeito desta abordagem, o texto como objeto sócio-histórico, não somente por se relacionar com o exterior, mas por trazer a historicidade em sua constituição. Contudo, por se tratar de uma prática de leitura que envolve esse romance, e não outro, é necessário que outra problematização seja somada às iniciais, a de como se dá o diálogo entre o leitor e um texto ficcional constituído mediante o espelhamento em um fato histórico.

Pão cozido debaixo de brasa é um romance que se estrutura a partir de um duplo programa narrativo - duas histórias que se alternam em capítulos - e traz em um deles a recriação do acidente radioativo com o Césio 137 ocorrido em Goiânia, no ano de 1987. Nessa narrativa, o dramático episódio goiano é ficcionalizado para constituir uma das tramas romanescas da obra, que se arquiteta com uma exposição de cunho crítico-social permeada por uma abordagem mística do evento ao associá-lo à chegada do terceiro milênio. Essa parte do romance e sua percepção pelo leitor é que se coloca no centro da presente abordagem.

Assim, este estudo resulta da observação da leitura realizada por alunos da terceira série do ensino médio do Cepae/UFG, leitores cuja prática se 
encontra determinada pelas coerções próprias do discurso pedagógico, especialmente por se tratar de uma atividade "obrigatória", mas que também se vêem instigados pela natureza transgressiva do discurso literário que, além da historicidade que lhe é constitutiva, nesse texto evidencia-se entrelaçado a outros fios discursivos tomados de um dado específico da realidade fatual. Trata-se, portanto, de uma tentativa de perceber o deslocamento do leitor entre as diversas ordens discursivas - a literária, a histórica e a escolar.

\section{DA PRÁTICA DESENVOLVIDA}

São inúmeras e de várias ordens as questôes que perpassam as práticas de leitura escolar. Não problematizá-las aqui não significa que as desconsideremos, mas interessa-me focalizar o que provocou a abordagem de que trata esta comunicação.

Entendendo que os sentidos são construídos no movimento da leitura e no espaço discursivo dos interlocutores, um princípio que determina as práticas de leitura realizadas em nossa escola é o de garantir efetivamente a participação do aluno-leitor na construção de sentidos dos textos dados a ler. Assim, são variadas as estratégias que precedem a atividade leitora, com o propósito de assegurar que a leitura se concretize como um ato significativo para o aluno. É freqüente, por exemplo, a provocação ao leitor com uma pequena mostra do texto, anunciando elementos da trama, do conflito, das personagens, especialmente quando se trata de uma leitura que demanda mais tempo como a de um romance, para que seja despertada certa curiosidade nos leitores.

Mas na prática em questão, optei por deixá-los sós nessa empreitada, visto que meu interesse era o de franquear aos alunos a descoberta de que o texto dado a ler consistia na recriação de um fato que, em certa medida, lhes era bastante próximo. À época do acidente, meus alunos tinham a idade de 3 a 4 anos, não tinham vivido, portanto, tão intensamente o drama que abalou toda a cidade de Goiânia, mas, como pude confirmar em seus depoimentos, todos tinham algum conhecimento do fato. Assim, a orientação para a leitura do romance foi a de que inicialmente tivessem um primeiro contato com o texto, fizessem sua primeira incursão no universo ficcional erigido pelo autor, sem qualquer antecipação da motivação que dera origem à criação da obra. A expectativa era a de que eles próprios percebessem na trama o evento real recriado pela ficção. O Prefácio que introduz o livro, caso meus alunos 


\section{Revista Soltaa Voz, v. 17, n. 2}

se dessem ao trabalho de lê-lo, o que seria pouco provável, nada lhes anteciparia, uma vez que não indicia o fato tramado. O que se esperava, portanto, era comprovar que no movimento da leitura ocorre um acionamento da memória discursiva, no sentido de saberes partilhados entre os interlocutores.

Muitas foram as dúvidas nas primeiras páginas, quase sempre acompanhadas de avaliaçôes pessoais, as quais eles manifestavam durante as aulas. Todos sabemos, leitores iniciados ou não, médios ou contumazes, do misto de prazer e temor diante das primeiras páginas de um livro, da sensação de clandestinidade de que não conseguimos escapar ao entrarmos em campos alheios que logo pilharemos, sentimentos que nos arrebatam quando da experiência da leitura. A idéia era guardar essas dúvidas dos alunos para que eles pudessem dividi-las com o próprio autor e experimentar, na prática, a compreensão do ato da leitura.

Como atividades posteriores à leitura do romance, foram propostos:

1. uma pesquisa sobre o acidente radioativo em Goiânia, com o intuito de que tivessem acesso a outros discursos sobre o evento, mais provavelmente o científico e o jornalístico;

2. uma produção escrita orientada pela seguinte questão: "Estabeleça uma relação entre a ficção e a realidade (um fato ocorrido em Goiânia) na história 2, do livro Pão cozido debaixo de brasa";

3. o encontro com o autor do livro;

4. a questão (parte do simulado do vestibular): "De que conflito trata a história das personagens Felipa e João Bertolino em Pão cozido debaixo de brasa?".

O que se pode considerar da pesquisa realizada é que ela contribuiu para informá-los sobre os fatos, aos quais a maioria tinha tido acesso apenas por intermédio de depoimentos dos familiares.

$\mathrm{Na}$ produção escrita, atendendo à orientação da questão, os alunos que realizaram esse trabalho expressaram sua percepção da construção do romance, referindo-se à "fusão entre o real e a ficção", a uma "remontagem do fato acontecido em Goiânia", a uma "mistura" entre a ficção e a realidade.

Nas respostas à questão do simulado, das quais trago algumas amostras, o que se observou, somando as duas turmas que perfazem um total de 52 alunos, foi que $50 \%$ das respostas relacionaram o conflito ao fato histórico, enquanto outros $50 \%$ não estabeleceram a relação esperada. 
Exemplos de respostas que atendem ao primeiro caso:

1. "Ele trata da exclusão social que obrigou os dois personagens a catar lixo para sobreviver; situação que possibilitou que encontrassem o 'Césio', o que gerou tragédia e mortes." (H.E.D., turma A)

2. "A história de Felipa e João Bertolino trata do acontecimento histórico do Césio-137, que aconteceu em Goiânia e teve repercussão no mundo inteiro. Esse casal de catadores de sucatas procurava a salvação, a passagem para o novo milênio e no meio dos escombros achou uma amostra do Césio, causando mortes e medo." (M.R.S., turma A)

3. "O conflito dado por Felipa e João Bertolino é a busca constante pela 'luz azul' que seria (garantiria) a passagem para o outro milênio, a chegada de coisas melhores, novas. Eles encontram a 'luz azul', que descobrem depois que é um elemento radioativo, o Césio 137, que traz para eles o terror e a morte." (N.L.S., turma A)

4. "Nesta história do livro Pão cozido debaixo de brasa de Miguel Jorge trata de um problema social e do Césio 137. O conflito se dá pela procura incessante de Felipa e João Bertolino da luz azul. Essa luz representa o Césio 137, mas para as personagens representa mudança de vida, vida melhor, sem tanto sofrimento." (C.M.C.P., turma A)

Em algumas respostas, percebe-se a simples identificação do acidente na narrativa, sem qualquer referência ao trabalho de recriação do autor quanto à apropriação do fato para a construção do conflito das personagens protagonistas, como se pode ver nos destaques:

1. "O conflito que trata a história dos dois personagens é o das diferenças sociais, junto a este, também o encontro das cápsulas de césio." (D.S.C., turma A, grifos nossos)

2. "A questão de que eles são uma família de catadores de papel para sobreviver e vivem em busca de uma melhora de vida, esse conto se passa na mesma época em que ocorre o acidente do césio 137." (K.M.M., turma A, grifos nossos)

Respostas em que não ocorreu a relação esperada:

1. "A história de Felipa e João Bertolino abrange um problema de ordem social que adquire maior proporção nas grandes cidades; o desemprego, a miséria e a falta de oportunidades àqueles que se vêem obrigados a 
140 RevistaSoltaa Voz, v. 17, n. 2

sair durante as noites revirando o lixo da cidade que dorme, alheia às condições de pobreza em que vivem tantas pessoas." (N.M.S., turma A)

2. "O conflito de Felipa e João Bertolino era encontrar a tal luz azul para que ela pudesse transportá-los para o terceiro milênio, onde achavam que não seriam mais pobres e teriam uma vida melhor." (M.A., turma A)

3. "Trata das dificuldades de um casal exposto às injustiças sociais, obrigados a catar lixo, o resto dos outros para poderem sobreviver e sustentar seus filhos." (J.G.N., turma A)

4. "O conflito é a constante busca da salvação, de um lugar maravilhoso, no meio de uma péssima condição de vida.” (A.B.S., turma A)

Diante do quadro de respostas, uma compreensão possível é a de que os alunos que identificaram a articulação do ficcional com o histórico teriam desenvolvido melhor sua capacidade interpretativa, vez que não apenas atribuíram sentidos ao que leram, mas perceberam o modo como o texto foi arquitetado para fazer sentido. Pode-se considerar que esses leitores, para falar com Pêcheux (1999), lançaram seu olhar-leitor às camadas do discurso nem sempre aparentes no texto, percebendo que é possível compreender as palavras em sua materialidade, em perpétuo jogo de transparência/opacidade. Isto porque eles teriam compreendido o entrecruzamento de dados ficcionais e reais para a constituição do conflito, mola propulsora da narrativa, ou seja, a inquestionável relação entre as condiçôes daquelas personagens e a existência real da cápsula de césio.

No caso dos que não estabeleceram a relação - além da constatação de que o jovem escolar encontra-se distanciado de fatos de sua história, ainda que alguns deles lhe sejam tão próximos -, poder-se-ia argumentar que o que ficou retido pela experiência de leitura foram os elementos próprios do discurso literário, e que isso já seria suficiente para um leitor escolar. Mesmo recolocando um fato histórico, a literatura guarda especificidades próprias em seu discurso que a resguardam da ordem dos outros discursos. Mas, considerando como Bakhtin (1988, p.106), que no gênero literário romanesco as vozes sociais e históricas que povoam a linguagem aí se organizam num sistema estilístico e expressam a "posição sócio-ideológica diferenciada do autor no seio dos diferentes discursos de sua época", a não-percepção do fundo histórico desse romance impede que o leitor atinja satisfatoriamente a função estética da obra. Sobretudo se concordamos que o fato histórico se coloca no coração do conflito narrativo da parte 2 de Pão cozido debaixo de brasa. 
Nas palavras de Pesavento (2000, p.7), história e literatura são formas de "dizer" a realidade, e por isso partilham a propriedade mágica da recriação do real, com o fim último de capturar a vida. E não foi outro o empenho do autor de Pão cozido debaixo de brasa, ao recriar e dar a ler sua percepção do acidente radioativo em Goiânia: capturar "gritos, dores, gozos, vozes, ritmos, entranhas e nervos postos a nu" (Joachim, 1997, p. 17) dos que viveram a tragédia e sofreram seus efeitos na própria pele.

Isso pôde ser comprovado no encontro com o autor, momento em que os alunos teriam liberdade para fazerem suas colocações e perguntas, e a primeira delas foi justamente sobre sua motivação para a escrita dessa parte do livro, em que há a recriação do acidente. Penso não ser necessário aqui aprofundar a polêmica questão da distância entre as intenções do autor, os efeitos de sentido do texto e os gestos de leitura do leitor, uma vez que já foi mencionada a compreensão de que a obra como individualidade não existe, só existe mediante sua relação com os seus intérpretes. Entretanto, não se pode desmerecer o impulso do autor para a criação, o que poderia ser entrevisto como indício das condições de produção do texto, no que se refere à imagem que esse autor faz de si, de seus interlocutores e do fato sobre o qual enuncia. Sobretudo, porque a resposta foi o profundo desconforto que teria lhe causado o fato e sua necessidade de contrapor seu discurso ao da mídia. Segundo Henry (1997, p.51-52), "não há 'fato' ou 'evento' histórico que não faça sentido, que não peça interpretação, que não reclame que lhe achemos causas e conseqüências". Talvez possamos considerar esse o impulso para o romance em questão.

Mas, poder-se-ia questionar, em que medida o encontro "físico" com o autor pode contribuir para a construção da interpretação? Interrogar o autor pode possibilitar ao leitor empreender movimentos no texto a fim de saber como funcionaram, para ele, os discursos, as determinações que constituíram sua ação criadora, mas sobretudo possibilita-lhe perceber a não-coincidência do olhar - dele, leitor, e do autor -, o que referenda a idéia de que a linguagem não é transparente.

Outra curiosidade demonstrada pelos alunos, e que serviu para reiterar a percepção da opacidade do discurso, refere-se à compreensão do título do livro. Muitos foram os depoimentos sobre a interpretação do enunciado que constitui o título do romance; alguns o relacionaram à primeira narrativa, outros à segunda; o próprio autor assegurou a liberdade do leitor, o que de certa forma gerou como que uma decepção dos alunos 


\section{Revista Soltaa Voz, v. 17, n. 2}

diante do que pareciam mais interrogaçōes do que respostas. Talvez por se tratar de leitores ainda pouco experientes, eles não têm clareza de que a literatura, mais do que responder, se presta a interrogar, pôr em questão, desestabilizar verdades.

Não cabe enumerar as tantas questões apresentadas pelos alunos ao autor. Essas duas observações aqui pontuadas são suficientes para assegurar que o objetivo do encontro entre autor e leitores, como estratégia de aproximação dos jovens alunos com a obra, foi alcançado, na medida em que se relativizou o conceito abstrato de obra, assim como o conceito de autor abstrato - e associado a isso a crença no sentido original -, e na medida em que o escritor Miguel Jorge ali se colocou também como um leitor, nem menos nem mais autorizado, a emitir sua interpretação. Trata-se de entender que houve alguns deslocamentos de posições na prática leitora, que aproximaram mais os alunos do universo ficcional daquele romance e que, conseqüentemente, possibilitaram-lhes construir alguns sentidos.

Contudo, não se pode deixar de observar o quanto o leitor pouco experiente tem a ilusão de que o autor tem o controle de seu discurso, assim como não se pode deixar de considerar que certamente essa "verdade" - tantas vezes reiterada no discurso pedagógico e perceptível na típica abordagem sustentada pela pergunta "O que o autor quis dizer?" - contribua para impedir ou no mínimo cercear a interpretação do leitor escolar.

\section{DAS CONCLUSŌES POSSÍVEIS}

Retomando as provocaçôes que motivaram este trabalho, se considerarmos a natureza dialógica da linguagem ou dialogicidade do texto, o caráter de respondibilidade próprio da atividade de leitura, não se poderia questionar se há ou não participação na construção de sentidos por parte do leitor, mesmo sendo ele inexperiente ou determinado por outra ordem, que não a do literário, coercitiva como é a do pedagógico. Mesmo assim, cabe ao professor aproveitar-se da natureza transgressora do discurso literário para permitir ao aluno-leitor subverter a natureza do discurso pedagógico, do qual ele mesmo - professor - é porta-voz.

Apesar da obediência ao programa ou do cumprimento das listas de leitura obrigatória, o professor de literatura sabe que, provocando o en- 
contro do aluno com o texto, cumprindo seu papel como mediador - no caso específico, atualizador da história presente no texto -, a consequiência será a de o jovem-leitor experimentar o gostoso, perigoso e muitas vezes doloroso risco de "arrebanhar os bens do Egito e com eles se regalar", para usar aqui as palavras de Certeau (2000), em seu belo ensaio sobre a leitura. Nesse sentido, a idéia de subversão, de clandestinidade do leitor; a idéia de que os sentidos pilhados no ato da leitura não dependeriam apenas da aquiescência do autor, não seriam autorizados pelo criador do texto mas erigidos no movimento da leitura, assegurando a construção de sentidos pelo leitor, mesmo estando ele sob a tutela do discurso escolar, ou pior, determinado pelo fim derradeiro de ser aprovado num concurso como o vestibular. Afinal,

a literatura não reside na perfeição da mensagem; ela não se aloja na adequação do dizer bem; ela está do lado do dizer mal - do excesso ou da carência, da lacuna ou da redundância, do muito cedo ou do muito tarde, do duplo sentido e do contratempo [...] A literatura, no seu discurso, trama estranhos circuitos, curiosos desenhos entre o locutor e o destinatário; desdobrando-os, escondendo um, representando o outro, jogando indefinidamente com a primeira pessoa e com as formas possíveis da interlocução (Foucault, apud Eribon, 1996, p.135-136).

\section{REFERÊNCIAS}

BAKHTIN, M. Questôes de literatura e estética: a teoria do romance. São Paulo: Ed. da UNESP, 1988.

(VOLOCHINOV, V. N.). Marxismo e filosofia da linguagem: problemas fundamentais do método sociológico na ciência da linguagem. 7. ed. São Paulo: Hucitec, 1995.

CERTEAU, M. A invenção do cotidiano: artes do fazer. 5. ed. Petrópolis: Vozes, 2000. v. 1.

ERIBON, D. O jogo da literatura (Foucault e Barthes). In: . Michel Foucault e seus contemporâneos. Rio de Janeiro: Zahar, 1996.

HENRY, P. A história não existe? In: ORLANDI, E. P. (Org.). Gestos de leitura: da história no discurso. 2. ed. Campinas, SP: Ed. da Unicamp, 1997. 
144 RevistaSoltaa Voz, v. 17, n. 2

JOACHIM, S. Pão cozido debaixo de brasa, ou a travessia dos Migrantes e Mutantes rumo ao novo milênio (Prefácio). In: JORGE, M. Pão cozido debaixo de brasa. Porto Alegre: Mercado Aberto, 1997.

JORGE, M. Pão cozido debaixo de brasa. Porto Alegre: Mercado Aberto, 1997.

PÊCHEUX, M. O discurso: leitura ou acontecimento. 2. ed. Campinas, SP: Pontes, 1997.

Sobre os contextos epistemológicos da Análise do Discurso. Escritos - Nudecri, Campinas, n. 4, p.7-16, 1999.

PENNAC, D. Como um romance. Rio de Janeiro: Rocco, 1998.

PESAVENTO, S. J. (Org.). Leituras cruzadas: diálogos da história com a literatura. Porto Alegre: Ed. UFRGS, 2000.

Recebido em: 20 jun. 2006

Aceito em: 7 nov. 2006 